\title{
FLOOD FREQUENCY ANALYSIS OF RIVER KOSI, UTTARAKHAND, INDIA USING STATISTICAL APPROACH
}

\author{
Saurabh Sah ${ }^{1}$, Jyothi Prasad ${ }^{2}$ \\ ${ }^{I}$ M. Tech Student (Hydraulic Engineering) Dept. of Civil EngineeringG.B.P.U.A. \&.T Pantnagar, Uttarakhand, India \\ saurabhsah9933@gmail.com \\ ${ }^{2}$ Professor Dept. of Civil Engineering College of TechnologyG.B.P.U.A. \&.T Pantnagar, Uttarakhand, India \\ jptce@gbpuat-tech.ac.in
}

\begin{abstract}
In the present study, flood frequency analysis has been applied for river Kosi in Uttarakhand. The river Kosi is an important tributary of Ganga river system, which arising from Koshimool near Kausani, Almora district flows on the western side of the study area and to meet at Ramganga River. The annual flood series analysis has been carried out to estimate the flood quantiles at different return period at Kosi barrage site of river Kosi. The statistical approach provided a significant advantage of estimation of flood at any sites in the homogenous region with very less or no data. In the at-site analysis of annual flood series the Normal, Log normal, Pearson type III, Log Pearson type III, Gumbel and Log Gumbel distribution were applied using method of moments . From the analysis of different goodness of fit tests, it has been found that the Log Gumbel distribution with method of moment as parameters estimation found to be the best-fit distribution for Kosi River and other sites in the region. It is recommended that the regional parameters for Kosi Basin may be used only for primary estimation of flood and should be reviewed when more regional data available.
\end{abstract}

Keywords: Flood Frequency Analysis, River Kosi, Annual Peak Flood discharge, Return Period, Goodness of fit Test.

\section{INTRODUCTION}

Flood is one of the natural disasters which occur in India every year. Flood in India generally occur during the southwest monsoon season (June to October). Floods are generated by the random coincidence of several meteorological factors, but man's use of the river catchments also has an impact upon the severity and consequences of the events. The risk of floods is treated as a hazards if it has the of the specified hazard occurrence. An accurate estimation of flood at a site is frequently required for the safe and economic design of various river engineering works. For the purpose of design of small bridges, culverts etc. it is sufficient to estimates the maximum instantaneous discharge the structure has to pass during its economic life period. One way of estimates the flood of specific recurrence interval is by performing flood frequency analysis of the recorded annual peak discharge over number of the years at the site under consideration. Generally in frequency analysis, an appropriate statistical distribution function is used to fit past available records and then inferences are made about the future likely flows.

\section{STUDY AREA AND DATA COLLECTION}

River Kosi is one of the major rivers of Kumaon region of Uttarakhand. It is an important tributary of Ganga river system, which arising from Koshimool near Kausani, Almora district flows on the western side of the study area and to meet at Ramganga River. It is a sub basin of the
Ganga River system. Geographically it is on the south east part of Nainital. It spreads from longitude $78^{\circ} 07^{\prime}$ to $80^{\circ} 29^{\prime}$ $\mathrm{N}$ and latitude $29^{\circ} 16^{\prime} \mathrm{E}$ to $30^{\circ} 05^{\prime} \mathrm{E}$. Geographical extent of this catchment is $6753 \mathrm{~km}^{2}$. For the study, annual peak discharge data of Kosi River at Kosi barrage Ramnagar from 1985-2014 (30 years flood data) were obtained from the measurements carried out by the Irrigation Department Ramnagar. The river is tributary of Ram Ganga River in Ganga river basin. Kosi River is the only available source of water for agricultural and industrial developments, in addition to fulfilling the needs of drinking water of the Ramnagar town and rural population of Bhabar area.

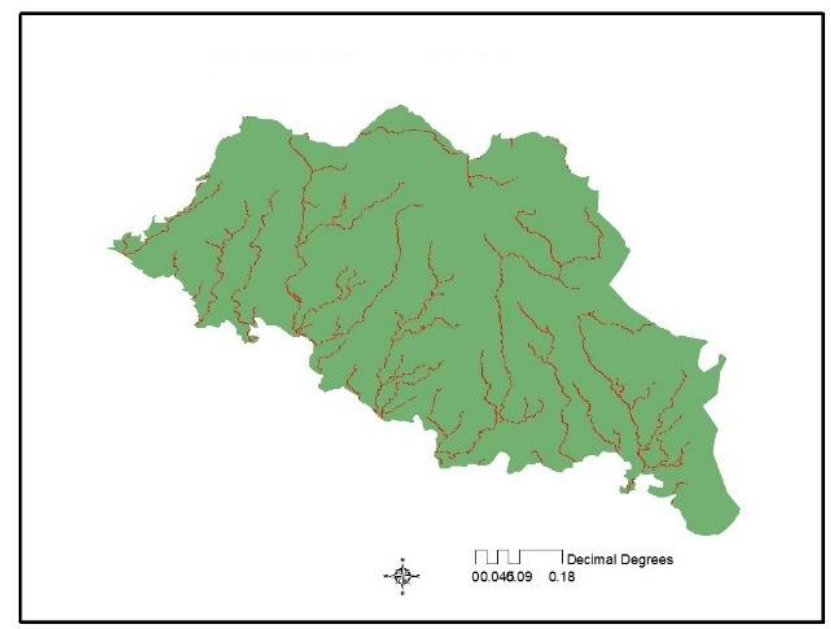

Figure- 1: Study Area 


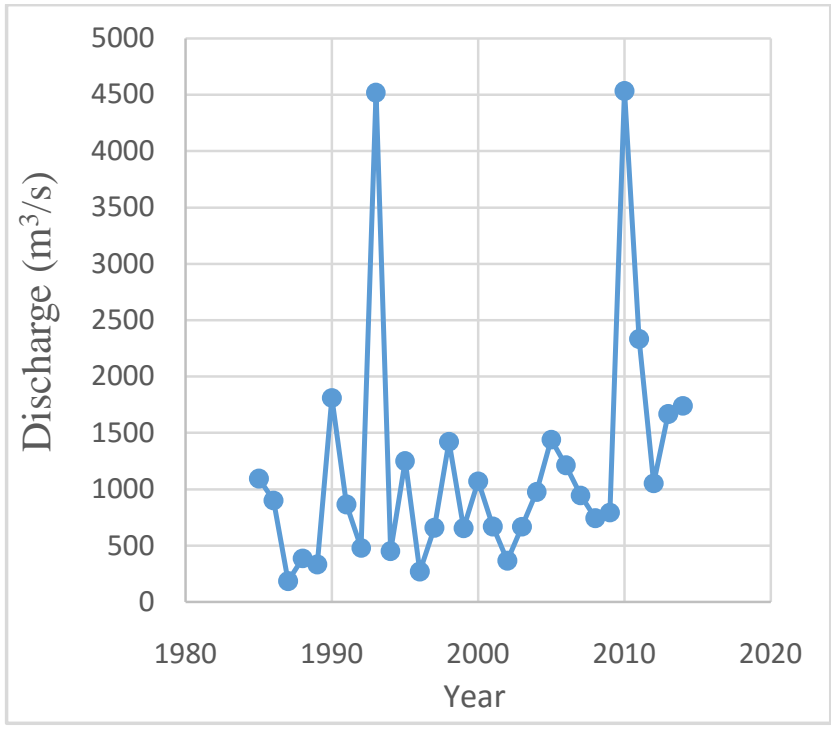

Figure- 2: Annual Peak discharge data at Kosi barrage (1985-2014)

\section{METHODOLOGY}

\section{Method of Moments}

The method of moments makes use of the fact that if all the moments of a distribution are known then everything about this distribution is known. For all the distribution in common usage four moments or fewer are sufficient all the oments. The method of moment's estimation is dependent on the assumption that the distribution of variate values in the sample is representative of the sample is representative of the population distribution. Given that the form of the distribution is known or assumed, the distribution which the sample follows is specified by its first two or three moments calculated from the data.

$$
X_{T}=\mu+K_{T} \sigma
$$

In which,

$X_{T}=$ the magnitude of flood at required return period $\mathrm{T}$.

$K_{T}=$ the frequency factor corresponding to $\mathrm{T}$.

$\mu$ and $\sigma=$ mean and standard deviation of the population.

\section{Test of Goodness of Fit}

The validity of probability distribution function proposed to fit the empirical frequency distribution of a given sample may be tested graphically or by analytical methods. The goodness fit measure involves identifying a distribution that fits the observed data. When computing the magnitudes of extreme events, such as flood flows, it is required that the probability distribution function be invertible, so that a given value of recurrence interval $(\mathrm{T})$ and the corresponding value of frequency factor $(\mathrm{K})$ can be determined. For plotting formula were adopted and compared to select the best flood frequency distribution that best fitted annual maximum flood flow of Kosi river catchment. A number of analytical tests have been proposed for testing the goodness of fit of proposed models. Three of these tests are presented. The Probability Density functions are used to fit the annual peak discharge series are shown in Table 1.

Table 1: Probability Density functions for selected

\begin{tabular}{|c|c|c|}
\hline S.N & Distributions & $f(x)$ \\
\hline 1 & Normal & $f(X)=\frac{1}{\sigma \sqrt{2 \pi}} \exp \left[-\frac{1}{2}\left(\frac{X-\mu}{\sigma}\right)^{2}\right]$ \\
\hline 2 & Log Normal & $f(X)=\frac{1}{\sigma_{y} \sqrt{2 \pi}} \exp \left[-\frac{1}{2}\left(\frac{\log _{e}(X)-\mu_{y}}{\sigma_{y}}\right)^{2}\right]$ \\
\hline 3 & $\begin{array}{l}\text { Pearson Type } \\
\text { III }\end{array}$ & $f(X)=\frac{\left(X-X_{o}\right)^{\gamma-1} e^{-\left(X-X_{o}\right) / \beta}}{\beta^{\gamma}(\gamma)}$ \\
\hline 4 & $\begin{array}{l}\text { Log Pearson } \\
\text { Type III }\end{array}$ & $\begin{array}{l}f(X) \\
=\frac{1}{|\beta|(\gamma) \cdot X}\left[\frac{\log _{e} X-y_{o}}{\beta}\right]^{\gamma-1} \exp \left[-\frac{\log _{e} X-y_{o}}{\beta}\right]\end{array}$ \\
\hline 5 & Gumbel & $f(X)=\frac{1}{\alpha} \exp \left[-\frac{X-U}{\alpha}-e-\frac{(X-U)}{\alpha}\right]$ \\
\hline 6 & Log Gumbel & $f(X)=\frac{1}{\alpha}\left[1-k\left(\frac{X-\mu}{\alpha}\right)\right]^{\frac{1}{K}-1} e\left[1-K\left(\frac{X-\mu}{\alpha}\right)\right]^{\frac{1}{K}}$ \\
\hline
\end{tabular}

\section{Chi- Square Test}

The chi- square goodness of fit test is one of the most commonly used tests for testing the goodness of fit of probability distribution functions to empirical frequency distribution.

$$
C=\sum_{j=1}^{m} \frac{\left(N_{j}-N P_{j}\right)^{2}}{N P_{j}}(2)
$$

where,

$\mathrm{N}_{\mathrm{J}}$ number of discharge lying in the $\mathrm{Q}$ domain for each class interval

$\mathrm{N}$ number of year

$\mathrm{M}$ number of classes

$\mathrm{C}$ is the Chi square

\section{D-Index Test}

In order to compare the relative fit of different distribution to hydrological data. The probability of exceedance of observation is estimated by Weibull plotting position formula. 


$$
P(X \geq x)=\frac{m}{(N+1)}
$$

where,

$\mathrm{P}$ is the probability of exceedance

$m$ is the rank of the flood values arranged in the descending order of magnitude, and $\mathrm{N}$ is the number of observations.

$$
D-\text { Index }=\frac{1}{X_{a v}}-\sum_{i=1}^{6} A B S\left(X_{i} \text { observed }-X_{i} \text {, computed }\right)
$$

\section{Kolmogorov-Smirnov Test}

This is a distribution free test widely used in statistical hydrology. It is based on the maximum difference between the cumulative distributions $\mathrm{Fe}(\mathrm{y})$ and the cumulative probability distribution being fitted $F_{y}\left(y ; \theta^{\prime}\right)$.

$$
D=\sum_{i=0}^{N}\left(F_{e}(y)-F_{y} ;\left(y_{i}, \theta^{\prime}\right)\right)
$$

The goodness of fit test of the selected probability model to the empirical distribution is accepted if:

$$
D \leq d_{\alpha}(N)
$$

where, $d_{\alpha}(N)$ is the Kolmogorov-Smirnov statistic corresponding to the sample size $\mathrm{N}$ and confidence level $y=(1-\alpha)$.

\section{RESULT AND DISCUSSION}

The computated Statistical parameters are shown in Table 2, The probability distribution method is carried out to determine the predicted discharge for the return period of $10,25,50,100,200,500,1000$ in years are shown in Table 3.

Table 2. Computation of Statistical parameter

\begin{tabular}{|c|c|c|c|c|}
\hline \multirow[b]{2}{*}{$\begin{array}{l}\text { Return } \\
\text { Period }\end{array}$} & \multirow[b]{2}{*}{$\begin{array}{c}\text { Computed } \\
\text { Discharge } \\
\left(\mathrm{m}^{3} / s\right)\end{array}$} & \multirow[b]{2}{*}{$\begin{array}{c}\text { Standard } \\
\text { Error } \\
\left(m^{3} / s\right)\end{array}$} & \multicolumn{2}{|c|}{ 95\% Significances Level } \\
\hline & & & $\begin{array}{c}\text { Upper } \\
\text { Confidence } \\
\text { Level }\left(m^{3} / s\right)\end{array}$ & $\begin{array}{c}\text { Lower } \\
\text { Confidence } \\
\text { Level }\left(m^{3} / s\right)\end{array}$ \\
\hline \multicolumn{5}{|c|}{ NORMAL DISTRIBUTION } \\
\hline 10 & 2502 & 254 & 3022 & 1982 \\
\hline 25 & 3527 & 357 & 4255 & 2799 \\
\hline 50 & 4317 & 446 & 5229 & 3406 \\
\hline 100 & 5113 & 541 & 6219 & 4008 \\
\hline 200 & 5919 & 640 & 7225 & 4612 \\
\hline 500 & 6991 & 773 & 8569 & 5413 \\
\hline 1000 & 10816 & 876 & 12603 & 9029 \\
\hline \multicolumn{5}{|c|}{ LOG NORMAL DISTRIBUTION } \\
\hline 10 & 2339 & 429 & 3216 & 1463 \\
\hline 25 & 3425 & 755 & 4966 & 1884 \\
\hline 50 & 4389 & 1085 & 6604 & 2174 \\
\hline 100 & 5506 & 1503 & 8573 & 2438 \\
\hline 200 & 6794 & 2023 & 10922 & 2666 \\
\hline 500 & 8798 & 2897 & 14703 & 2882 \\
\hline 1000 & 10573 & 3723 & 18170 & 2976 \\
\hline \multicolumn{5}{|c|}{ PEARSON TYPE III DISTRIBUTION } \\
\hline 10 & 2502 & 510 & 3544 & 1460 \\
\hline 25 & 3527 & 898 & 5360 & 1694 \\
\hline 50 & 4317 & 1132 & 6582 & 2052 \\
\hline 100 & 5116 & 1334 & 7839 & 2394 \\
\hline 200 & 5922 & 1614 & 9215 & 2628 \\
\hline 500 & 6994 & 1946 & 10965 & 3022 \\
\hline 1000 & 7809 & 2272 & 12352 & 3267 \\
\hline \multicolumn{5}{|c|}{ LOG PEARSON TYPE III DISTRIBUTION } \\
\hline 10 & 2351 & 479 & 3309 & 1392 \\
\hline 25 & 3425 & 950 & 5364 & 1485 \\
\hline 50 & 4389 & 1243 & 6925 & 1853 \\
\hline 100 & 5506 & 1575 & 8721 & 2291 \\
\hline 200 & 6794 & 2017 & 10910 & 2678 \\
\hline 500 & 8798 & 2407 & 13710 & 3895 \\
\hline 1000 & 10573 & 3055 & 16807 & 4339 \\
\hline \multicolumn{5}{|c|}{ GUMBEL DISTRIBUTION } \\
\hline 10 & 2541 & 396 & 3350 & 1733 \\
\hline 25 & 3310 & 534 & 4400 & 2220 \\
\hline 50 & 3880 & 651 & 5209 & 2551 \\
\hline 100 & 4446 & 744 & 5966 & 2926 \\
\hline 200 & 5010 & 850 & 6745 & 3275 \\
\hline 500 & 5754 & 990 & 7775 & 3733 \\
\hline 1000 & 6316 & 1097 & 8555 & 4078 \\
\hline \multicolumn{5}{|c|}{ LOG GUMBEL DISTRIBUTION } \\
\hline 10 & 2362 & 396 & 3170 & 1553 \\
\hline 25 & 4077 & 534 & 5167 & 2987 \\
\hline 50 & 6114 & 629 & 7399 & 4829 \\
\hline 100 & 9140 & 744 & 10660 & 7621 \\
\hline 200 & 13648 & 850 & 15383 & 11912 \\
\hline 500 & 23149 & 990 & 25710 & 21127 \\
\hline 1000 & 34517 & 1097 & 36755 & 32278 \\
\hline
\end{tabular}

\begin{tabular}{|l|c|c|}
\hline Parameter & $\begin{array}{l}\text { Original } \\
\text { series }\end{array}$ & $\begin{array}{l}\text { Log transformed } \\
\text { series }\end{array}$ \\
\hline Mean & 1185.13 & 6.80 \\
\hline Standard Deviation & 1039.75 & 0.73 \\
\hline $\begin{array}{l}\text { Coefficient of } \\
\text { Variation }\end{array}$ & 0.87 & 0.10 \\
\hline $\begin{array}{l}\text { Skewness } \\
\text { Coefficient }\end{array}$ & 2.35 & 0.17 \\
\hline Kurtosis Coefficient & 8.97 & 3.55 \\
\hline
\end{tabular}

Table 3: Estimation of T-Year Flood and its Standard Error of Kosi River 


\section{Test of Goodness of Fit Test}

Tests of Goodness fit namely Chi squared test, K-S test and D-index test have been applied to the chosen probability distributions for Kosi river stations are presented as summary in Table 4. Form this table it has been observed that Kosi River stations log normal and log Gumbel are fitted from both K-S test and D-index test.

The D-index fitness tests applied for the river stations are tested for model efficiency, Root mean square error (RMSE) and D-index (fit in the top six values) for different distributions.

It has been found that from the Table 4 for river Kosi, Log Gumbel distribution having Model efficiency $96.24 \%$ and root mean square error $90.38 \%$.

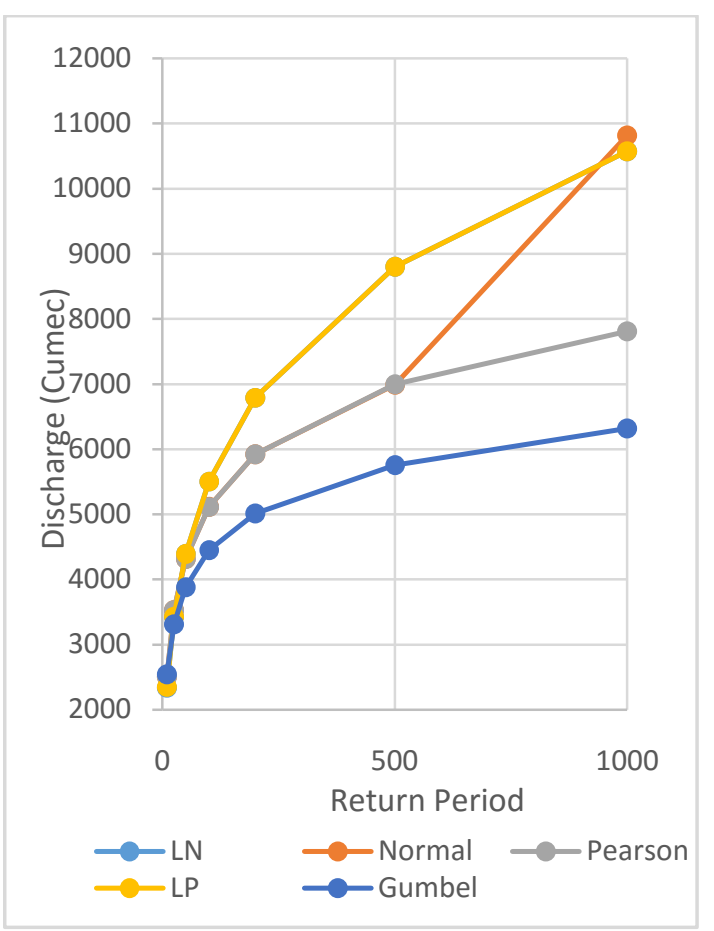

Figure -3 discharge vs. return period

Table 4: Model efficiency, RMSE for D-index of different distributions for Kosi River.

\begin{tabular}{|c|c|c|c|c|}
\hline S.No. & Distribution & $\begin{array}{c}\text { Model } \\
\text { Efficiency (\%) }\end{array}$ & RMSE & $\begin{array}{c}\text { D- } \\
\text { index }\end{array}$ \\
\hline 1 & Normal & 90.21 & 133.84 & 4.62 \\
\hline 2 & Log Normal & 91.37 & 118.43 & 3.09 \\
\hline 3 & $\begin{array}{c}\text { Pearson Type } \\
\text { III }\end{array}$ & 92.23 & 127.62 & 3.81 \\
\hline 4 & $\begin{array}{c}\text { Log Pearson } \\
\text { Type III }\end{array}$ & 91.98 & 117.43 & 3.25 \\
\hline 5 & Gumbel & 92.61 & 121.14 & 3.43 \\
\hline 6 & Log Gumbel & 96.24 & 90.38 & 1.63 \\
\hline
\end{tabular}

\section{Coefficient of Determination}

From trend line equation, Coefficient of determination $\left(\mathrm{R}^{2}\right)$ values obtained from the Figure 3 are given in Table 5. The value $\left(R^{2}\right)$ shows that a pattern of the scattered and narrow. It has been found that Log Gumbel distribution having maximum $\left(R^{2}\right)$ value is 0.9662 . Hence for predicting expected flow in the Kosi Rivers Log Gumbel is the best suitable distribution.

Table 5: Coefficient of Determination

\begin{tabular}{|c|c|c|c|c|c|c|}
\hline \multicolumn{7}{|c|}{$\begin{array}{c}\text { Coefficient of Determination } \\
\left(R^{2}\right)\end{array}$} \\
\hline \multirow[b]{2}{*}{ River } & \multicolumn{6}{|c|}{ Distribution } \\
\hline & Normal & $\begin{array}{c}\text { Log } \\
\text { Normal }\end{array}$ & $\begin{array}{c}\text { Pearson } \\
\text { Type } \\
\text { III }\end{array}$ & $\begin{array}{c}\text { Log } \\
\text { Pearson } \\
\text { Type } \\
\text { III } \\
\end{array}$ & Gumbel & $\begin{array}{l}\text { Log } \\
\text { Gumbel }\end{array}$ \\
\hline Kosi & 0.9339 & 0.8510 & 0.7553 & 0.8515 & 0.7444 & 0.9662 \\
\hline
\end{tabular}

\section{CONCLUSION}

- In this study six distributions are considered and worked out the flood quantiles for different return period like 1000, 500, 200, 100, 75, 50, 25 and 10 years, here it is assumed that all the distributions are fittings for Kosi River.

- Tests of Goodness fit namely Chi squared test, K-S test and D-index test applied to the chosen probability distributions, it shows that Log normal and Log Gumbel distributions are fitted for both K-S test and D-index tests. However from the most of literature review recommends the use Log Gumbel distribution for estimation of flood quantities.

- Hence Log Gumbel distribution is the best distributions for predicting floods in Kosi River.

\section{REFERENCES}

[1] Dalrymple T. (1960), "Flood frequency methods", U. S. Geol. Surv. Water supply pap, 1543A, U.S. Govt. Printing office, Washington, D.C., $11-51$.

[2] Jyothi Prasad(1994) unpublished M.E (Hydrology) thesis submitted to "Regional flood frequency Analysis for Central India to Department of Hydrology, University of Roorkee.

[3] Mukherjee. M. K. Model of Peak Discharge (Qp) $\&$ Return Period (T) of river Subernarekha, India. International Journal of Current Research. Vol-4. Issue 04. PP-164, April, 2012.

[4] P V Parameshwaran, J P Singh, Jyothi Prasad, H J Shiva Prasad "Flood Frequency Studies of Upper Godavari Basins in Maharashtra"- at National Workshop collaboration held at Delhi College of Engineering, Delhi during October 8-9, 1999. 